\title{
Additive and intensive grinding effects on the synthesis of cordierite
}

\author{
Emre Yalamaç*, Sedat Akkurt ${ }^{1}$ \\ Mechanical Engineering Department, Izmir Institute of Technology, 35430 Izmir, Turkey
}

Received 28 February 2005; received in revised form 16 March 2005; accepted 6 June 2005

Available online 18 August 2005

\begin{abstract}
Cordierite was mechanochemically synthesized by mixing proper amounts of kaolin, talc and $\mathrm{Al}(\mathrm{OH})_{3}$. Full factorial experiments were planned, conducted, and the results were analyzed by the use of statistical techniques in order to understand the effects of process variables on the amount of synthesized product. The powder products were analyzed by XRD, DTA, and SEM-EDS. As a result of the statistical analysis, temperature was found to be the most important factor. Based on XRD peak intensity measurements, the cordierite mixture was completely amorphized by grinding at $300 \mathrm{rpm}$ for $60 \mathrm{~min}$. Cordierite was successfully produced at temperatures as low as $1150{ }^{\circ} \mathrm{C}$ by using the mixture after intensive grinding. The combined effect of magnesium borate additive and grinding on cordierite synthesis was also studied. These factors successfully decreased the synthesis temperature down to $1000{ }^{\circ} \mathrm{C}$.
\end{abstract}

(C) 2005 Elsevier Ltd and Techna Group S.r.l. All rights reserved.

Keywords: A. Powders: Solid state reaction; A. Milling; D. Cordierite; Statistical experimental design

\section{Introduction}

Cordierite has traditionally been used in those applications that require low thermal expansion coefficient. It is also attractive in new potential applications as a substrate material in microelectronics [1]. Cordierite combines relatively low thermal expansion needed for thermal shock resistance with relatively high refractoriness for operating in severe exhaust environments at high temperatures [2]. The production of cordierite can be done by directly mixing of:

(1) simple compounds like oxides, hydroxides and carbonates;

(2) double compounds like clays, talc, steatite, sepiolite, spinel, mullite, forsterite;

(3) triple compounds such as chlorite.

\footnotetext{
* Corresponding author. Tel.: +90 232 7506606; fax: +90 2327506505. E-mail addresses: emreyalamac@iyte.edu.tr (E. Yalamaç), sedatakkurt@iyte.edu.tr (S. Akkurt).

${ }^{1}$ Tel.: +90 232 7506523; fax: +90 2327506505 .
}

The most commonly employed mixtures are as follows [2-4]:

(1) Clay + Talc + (Alumina or Silica)

(2) Clay $+\mathrm{Mg}(\mathrm{OH})_{2}+$ minor additives

Minor adjustments to meet stoichiometry are done via addition of different sources of silica, alumina or magnesia.

A wide range of synthesis methods have been proposed in order to decrease the synthesis temperature, and improve the physical cordierite properties. Production methods such as: co-precipitation [5], sol-gel [6] or solid state synthesis [7] were investigated. The temperature required for complete transformation of components to cordierite via solid state synthesis was generally higher than $1300^{\circ} \mathrm{C}$ [8].

Awano et al. [5] employed a mixed silica sol, boehmite sol, and magnesium nitrate solution for co-precipitation and gelation of precursor-gel via an adjustment of solution $\mathrm{pH}$. Cordierite powder was obtained by grinding and calcinations of the precursor-gel. Kurama and Ay [9] proposed the use of two different sources of $\mathrm{MgO}$ and kaolin to form 
cordierite. They also investigated the effect of grinding time for cordierite formation. In a more recent study, Tamborenea et al. [10] investigated the influence of mechanical treatment by grinding on the formation of cordierite from a talc, kaolinitic clay and gibbsite mixture. The mixture was ground by oscillating mill with a frequency of $12.5 \mathrm{~s}^{-1}$ for 5-20 min. According to their study, the raw materials' crystalline structure was lost and the reactivity increased due to the milling and finally cordierite was synthesized at $1215^{\circ} \mathrm{C}$. None of the three studies outlined above, however, employed intensive grinding.

Mechanochemistry is a branch of science dealing with chemical reactions of solids, which take place under mechanical activation. It is the subject of increasing interest in relation to solid state science and technology. Mechanochemical synthesis has great potential for novel powder synthesis at low temperature in addition to benefits derived from decreasing sintering temperatures and denser bodies. Intense grinding activates ceramic powders which enhances the development of solid-state processes. The mechanical energy produces structural imperfections in the powder particles during grinding and this effect increases the reactivity of ground materials. In addition, grinding which is based on impact and friction, increases the chemical reaction rates via particle size reduction, which increases the specific surface area [11].

Many electronic ceramics, which may be co-fired with metals at reduced temperatures, are formulated with low melting glasses as densification aids [12]. In the cordierite synthesis additives like $\mathrm{B}_{2} \mathrm{O}_{3}$ and $\mathrm{P}_{2} \mathrm{O}_{5}$ were used for increasing phase-transformation kinetics and increasing bulk density [13]. Sumi et al. synthesized magnesium borate $\left(2 \mathrm{MgO} \cdot \mathrm{B}_{2} \mathrm{O}_{3}\right)$ by using boric acid $\left(\mathrm{H}_{3} \mathrm{BO}_{3}\right)$ and $\mathrm{Mg}(\mathrm{OH})_{2}$ solutions before using the former as an additive for cordierite synthesis [14]. Kurama et al. [15] also used the same method. However, they mixed boric acid $\left(\mathrm{H}_{3} \mathrm{BO}_{3}\right)$ solution with synthesized $\mathrm{Mg}(\mathrm{OH})_{2}$ powders. After mixing, the same procedure as that followed in ref. [14] was applied for $2 \mathrm{MgO} \cdot \mathrm{B}_{2} \mathrm{O}_{3}$ synthesis.

Above mentioned studies, either used additives, or intensive grinding for cordierite synthesis but none utilized the two together. In this study, mechanochemical techniques and additives like $2 \mathrm{MgO} \cdot \mathrm{B}_{2} \mathrm{O}_{3}$ were used to decrease the synthesis temperature of cordierite. Full factorial experimental design was used for planning the tests, and the resulting data were analyzed using ANOVA (analysis of variance) table.

\section{Experimental procedure}

\subsection{Materials}

Sivas Kaolin $\left(\mathrm{Al}_{2} \mathrm{O}_{3} \cdot 2 \mathrm{SiO}_{2} \cdot 2 \mathrm{H}_{2} \mathrm{O}\right)$ [16], Egyptian Talc $\left(3 \mathrm{MgO} \cdot 4 \mathrm{SiO}_{2} \cdot \mathrm{H}_{2} \mathrm{O}\right)$ [17], and reagent grade aluminium hydroxide (Gibbsite) $\left(\mathrm{Al}(\mathrm{OH})_{3}\right)$ (MERCK) were used as raw materials for cordierite synthesis. Synthesized magnesium borate $\left(2 \mathrm{MgO} \cdot \mathrm{B}_{2} \mathrm{O}_{3}\right)$ was used as an additive to decrease cordierite synthesis temperature. In this study, magnesium borate powder was produced in-house by mixing boric acid $\left(\mathrm{H}_{3} \mathrm{BO}_{3}\right)$ solution and magnesium hydroxide $\mathrm{Mg}(\mathrm{OH})_{2}$ powder. The chemical properties of these raw materials are listed in Table 1. More details of the experimental procedure are outlined elsewhere $[18,19]$.

\subsection{Method}

Powder mixture was mixed in stoichiometric proportions to attain 1:1:2 cordierite composition. A typical batch consisted of $2.39 \mathrm{~g}$ of OMYA talc, $1.54 \mathrm{~g}$ of Sivas Kaolin and $2.07 \mathrm{~g}$ of gibbsite. As-mixed stoichiometric mixtures were mechanically activated in the planetary mono mill (Fritsch Pulverisette 6). Thirty tungsten carbide balls $(\varnothing$ : $10 \mathrm{~mm}$ ) were used as the grinding media in a $250 \mathrm{ml}$ tungsten carbide mill container. Grinding time (minute) and grinding rotational speed (rate per minute) were the factors chosen for statistical experimental design. These were changed from 300 to $500 \mathrm{rpm}$ and 15 to $60 \mathrm{~min}$, respectively.

Mechanically activated powder mixtures were uniaxially pressed (Yildiz Hidrolik San. Tic, 2001 Model) at $120 \mathrm{MPa}$ in a stainless steel die (Ø: $12 \mathrm{~mm})$. The compacted pellets were heated in a 51 Globar benchtop kiln (Alser Teknik A.Ş. Protherm PLF 160/5). The pelletized cordierite mixtures were heated in a temperature range of $1000-1200{ }^{\circ} \mathrm{C}$. The soak time was $4 \mathrm{~h}$. The heating rate was $10{ }^{\circ} \mathrm{C} / \mathrm{min}$. The kiln was allowed to cool by itself.

\subsection{Statistical experimental design}

In this study we started with the initial series of eight experiments designed according to the $2^{3}$ full-factorial experimental design using the factors listed in Table 2 . The aim was to identify the more important factor effects in addition to recognizing if there was any significant interaction between the factors. This kind of experimental

Table 1

Chemical analyses of used raw materials $[16,17]$

\begin{tabular}{lcc}
\hline & $\begin{array}{l}\text { E. Talc Published } \\
\text { Analysis (OMYA) (wt.\%) }\end{array}$ & Sivas Kaolin (wt.\%) \\
\hline $\mathrm{Al}_{2} \mathrm{O}_{3}$ & 0.94 & 33.07 \\
$\mathrm{SiO}_{2}$ & 58.94 & 52.86 \\
$\mathrm{MgO}$ & 31.18 & 0.00 \\
$\mathrm{Na}_{2} \mathrm{O}$ & 0.00 & 0.13 \\
$\mathrm{~K}_{2} \mathrm{O}$ & 0.00 & 0.12 \\
$\mathrm{CaO}$ & 1.57 & 0.47 \\
$\mathrm{Fe}_{2} \mathrm{O}_{3}$ & 0.40 & 0.05 \\
$\mathrm{TiO}_{2}$ & 0.00 & 0.38 \\
$\mathrm{MnO}$ & 0.00 & 0.10 \\
$\mathrm{SO}_{3}$ & 0.00 & 0.60 \\
$\mathrm{~B}_{2} \mathrm{O}_{3}$ & 0.00 & 0.00 \\
$\mathrm{LOI}$ & 6.97 & 12.22 \\
$\mathrm{Total}$ & 100.00 & 100.00 \\
\hline
\end{tabular}


Table 2

Factor ranges used in $2^{3}$ full factorial experiments

\begin{tabular}{lcc}
\hline Factor & Low level & High level \\
\hline A: grinding speed $(\mathrm{rpm})$ & 300 & 500 \\
B: grinding time $(\min )$ & 15 & 60 \\
C: heating temperature $\left({ }^{\circ} \mathrm{C}\right)$ & 1100 & 1200 \\
\hline
\end{tabular}

design is used by several researchers [20], and it uses the complete $2^{p}$ factorial experiments which means each of $p$ number of factors is tested at two levels [21]. The results can provide the significant main effects, two factor interactions, and also three factor interactions clear of each other. The experiments were done under the conditions that are listed in Tables 2-4.

Other additional sets of experiments were done for the purpose of comparing the effect of heating temperature and additives on the formation of cordierite.

$\mathrm{X}$-ray diffraction (XRD) with $\mathrm{Cu} \mathrm{K} \alpha$ radiation was used to detect the present phases and the crystallinity of the ground and heated mixtures (Philips X'pert Pro, XRD). The response variable for statistical analysis was the intensity of the $\left(\begin{array}{lll}1 & 0 & 0\end{array}\right)$ peak of cordierite at $2 \theta=10.44^{\circ}$ (see, e.g. JCPDS card: 82-1884).

DTA analysis was carried out in order to investigate the thermal behaviour of the mixtures (Shimadzu DTA-50, Japan). Heating was done under argon gas atmosphere at a rate of $10{ }^{\circ} \mathrm{C} / \mathrm{min}$. The morphology of the mixtures was observed by scanning electron microscope (Philips XL-30S FEG, SEM).

\section{Results and discussion}

\subsection{Coding system used for samples}

Because of the large number of studied samples a coding system was used. There were a total of five studied parameters:

(1) grinding rotational speed (0-500 rpm);

(2) grinding duration $(0-60 \mathrm{~min})$;

(3) soak temperature $\left(0-1200{ }^{\circ} \mathrm{C}\right)$;

(4) soak time $(0-4 \mathrm{~h})$;

(5) percentage additives used (0-5 wt. $\left.\% 2 \mathrm{MgO} \cdot \mathrm{B}_{2} \mathrm{O}_{3}\right)$.
For example, the sample coded as 300-60-1150-4-0 indicates that a mixture was ground at $300 \mathrm{rpm}$ for $60 \mathrm{~min}$ in the mill before compaction in a cylindrical die. The pellet was then heated in a kiln at $1150{ }^{\circ} \mathrm{C}$ for $4 \mathrm{~h}$. No additive was used for this sample.

\subsection{X-ray diffraction analysis}

\subsubsection{Results of factorial designed experiments for synthesis of cordierite}

In order to minimize the number of runs experimental design methodology was employed. The soak time was $4 \mathrm{~h}$, heating rate was $10^{\circ} \mathrm{C} / \mathrm{min}$, grinding feed to media volume ratio (1:6) and ball size $(\varnothing: 10 \mathrm{~mm})$ were all fixed. The single replicate of the $2^{3}$ design was generated using commercial software called Design-Expert ${ }^{(\mathrm{R})}$ 6.0. The three factors were grinding speed (A); grinding duration (B); and soak temperature (C). Each factor was studied at two levels. The design matrix is shown in Tables 3 and 4.

XRD patterns for as-mixed and ground mixtures (300-150-0-0 to 500-60-0-0-0) are shown in Fig. 1. As was expected for raw materials mixtures, kaolinite, talc and gibbsite were detected. As shown in Fig. 1 for sample 300-15-0-0-0, the peak intensities of raw materials decreased. Further grinding of this mixture resulted in a completely amorphized powder. Samples that were ground more vigorously than $300 \mathrm{rpm}$ and $60 \mathrm{~min}$ were all totally amorphized.

These ground mixtures (300-15-0-0-0 to 500-60-0-0-0) were later fired at 1100 and $1200{ }^{\circ} \mathrm{C}$ for $4 \mathrm{~h}$, and the resulting XRD charts are shown in Figs. 2 and 3, respectively. Small amount of cordierite phase was detected in the 300-60-11004-0 and 500-15-1100-4-0 specimens in addition to main spinel and cristobalite phases in Fig. 2. Hence, the $1100{ }^{\circ} \mathrm{C}$ heat treatment was not sufficient for cordierite synthesis. At that temperature, the raw materials did not completely react with each other. On the contrary, all samples that were heated at $1200{ }^{\circ} \mathrm{C}$ (300-15-1200-4-0 to 500-60-1200-4-0) showed cordierite and a small of amount spinel phase.

The data obtained from a single replicate of the $2^{3}$ factorial experiment are shown in Table 5. The values for the response variable were measured from the main peak intensities of cordierite from (lllll 00 ) planes in the XRD patterns in Figs. 2 and 3 . The eight runs were made in random order. The designed set of experiments demonstrated the effects of

Table 3

Experimental conditions in $2^{3}$ full factorial design

\begin{tabular}{llll}
\hline Run number & A: grinding speed $(\mathrm{rpm})$ & B: grinding time $(\mathrm{min})$ & $\mathrm{C}:$ heating temperature $\left({ }^{\circ} \mathrm{C}\right)$ \\
\hline 1 & 300 & 15 & 15 \\
2 & 500 & 60 & 1100 \\
3 & 300 & 60 & 1100 \\
4 & 500 & 15 & 1100 \\
5 & 300 & 15 & 1200 \\
6 & 500 & 60 & 1200 \\
7 & 300 & 60 & 1200 \\
8 & 500 & 1200
\end{tabular}


Table 4

Codes for each sample tested in $2^{3}$ full factorial experiments

\begin{tabular}{lrr}
\hline & & High $1200{ }^{\circ} \mathrm{C}$ \\
\hline Rotational speed low $300 \mathrm{rpm}$ & & $3100{ }^{\circ} \mathrm{C}$ \\
$\quad$ High 60-min grinding & $300-60-0-0-0$ & $300-60-1200-4-0$ \\
Low 15-min grinding & $300-15-0-0-0$ & $300-15-1200-4-0$ \\
Rotational speed high 500 rpm & & $300-60-1100-4-0$ \\
High 60-min grinding & $500-60-0-0-0$ & $500-60-1200-4-0$ \\
Low 15-min grinding & $500-15-0-0-0$ & $500-15-1200-4-0$ \\
\hline
\end{tabular}

factors on the response variable as shown in Table 5. The normal probability plot of these effects is shown in Fig. 4. Such a plot graphically shows the significant factor effects that are positioned away from the diagonal line. If a factor effect is located near this diagonal line, then its effect on the response is known as statistically insignificant. The important effects that emerge from this analysis were the main effects of C (soak temperature), and to a less degree the $\mathrm{AB}$ interaction (grinding speed and grinding time) and maybe $\mathrm{ABC}$ interaction.

The statistical analyses results (ANOVA table) for the cordierite synthesis rate data are given in Table 6. Mean square values were obtained by dividing the sum of squares by the degrees of freedom. The model $F$-value of 402.92 implied that the model was significant. There was

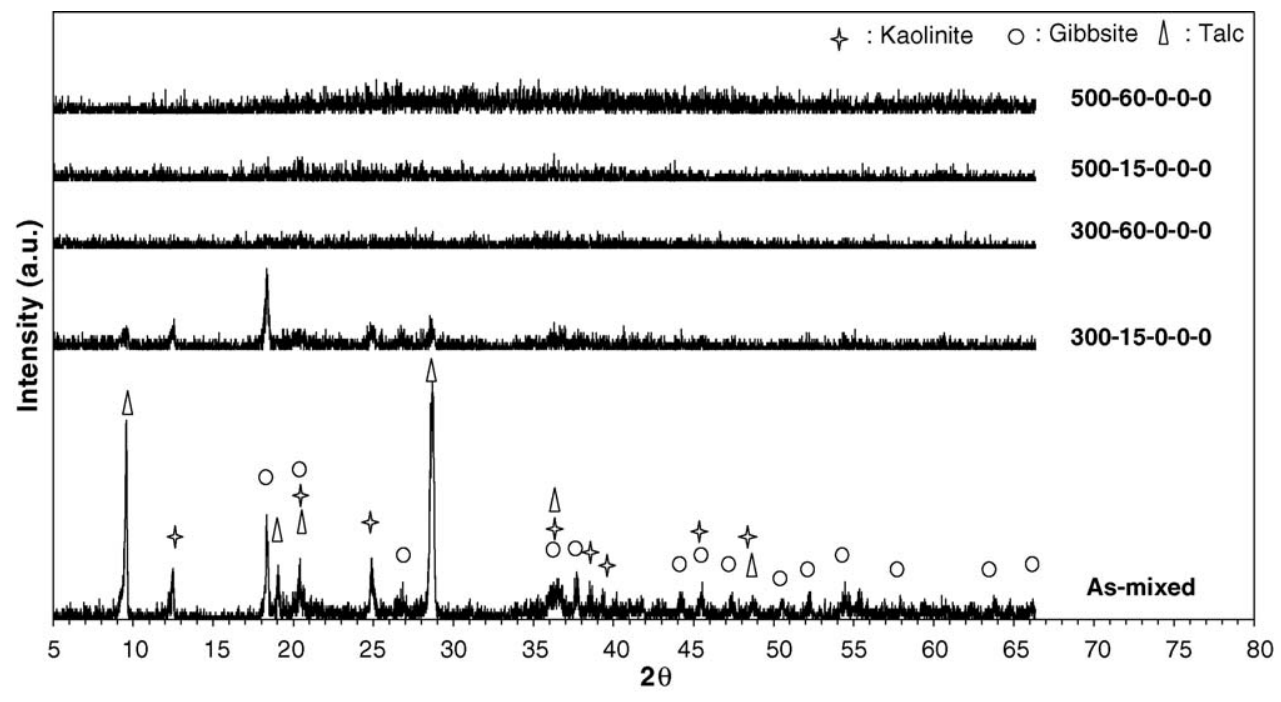

Fig. 1. XRD patterns of the samples that were ground at different conditions.

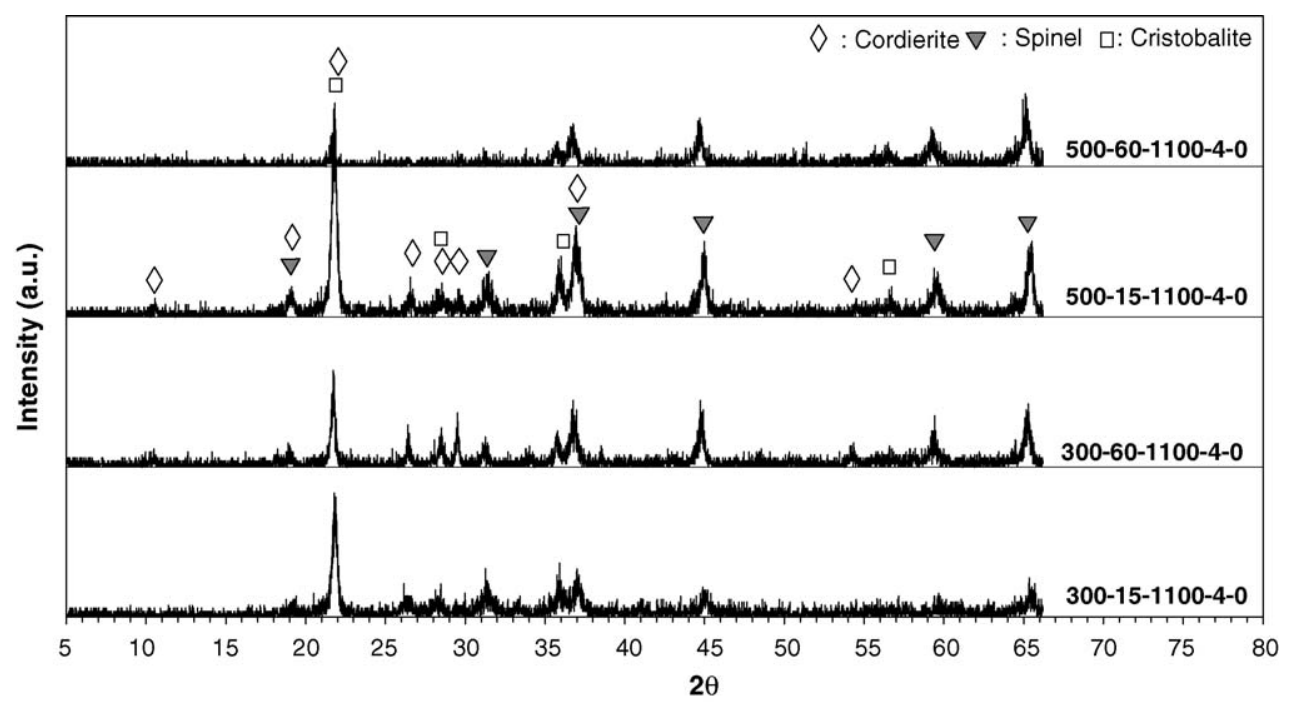

Fig. 2. XRD patterns of the ground samples that were heat treated at $1100{ }^{\circ} \mathrm{C}$. 


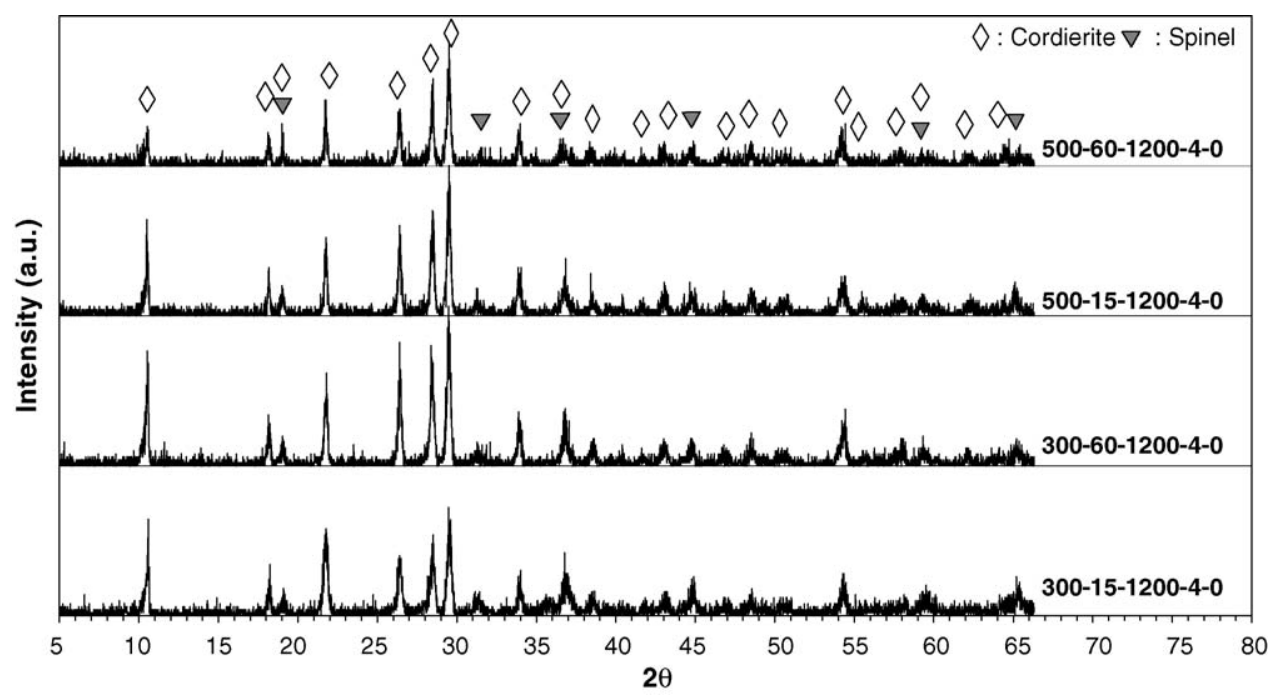

Fig. 3. XRD patterns of the ground samples that were heat treated at $1200{ }^{\circ} \mathrm{C}$.

Table 5

Results of designed set of experiments for cordierite synthesis

\begin{tabular}{|c|c|c|c|c|c|}
\hline \multirow[t]{2}{*}{ Run number } & \multicolumn{3}{|c|}{ Factor } & \multirow[t]{2}{*}{ Run label } & \multirow[t]{2}{*}{ Response } \\
\hline & A & B & $\mathrm{C}$ & & \\
\hline 1 & - & - & - & (1) & 0.00 \\
\hline 2 & + & - & - & $\mathrm{A}$ & 6.15 \\
\hline 3 & - & + & - & B & 4.03 \\
\hline 4 & + & + & - & $a b$ & 0.00 \\
\hline 5 & - & - & + & $\mathrm{C}$ & 30.13 \\
\hline 6 & + & - & + & ac & 44.96 \\
\hline 7 & - & + & + & $\mathrm{bc}$ & 63.81 \\
\hline 8 & + & + & + & $a b c$ & 16.99 \\
\hline
\end{tabular}

only a $3.81 \%$ chance that a "model $F$-value" this large occurred due to noise. The importance of each term, i.e., the influence of cross interaction between/among the components on the cordierite synthesis rate is shown by the values in column "Prob $>F$ ". Values of "Prob $>F$ " less than 0.05 indicated that model terms were significant at the $95 \%$ confidence level. In other words we are $95 \%$ confident that the particular effect was significant. In this case, the main effect soak temperature (C) had the largest influence on the cordierite synthesis since the value of Prob $>F$ was the smallest for model term C ( $p=0.0157)$.

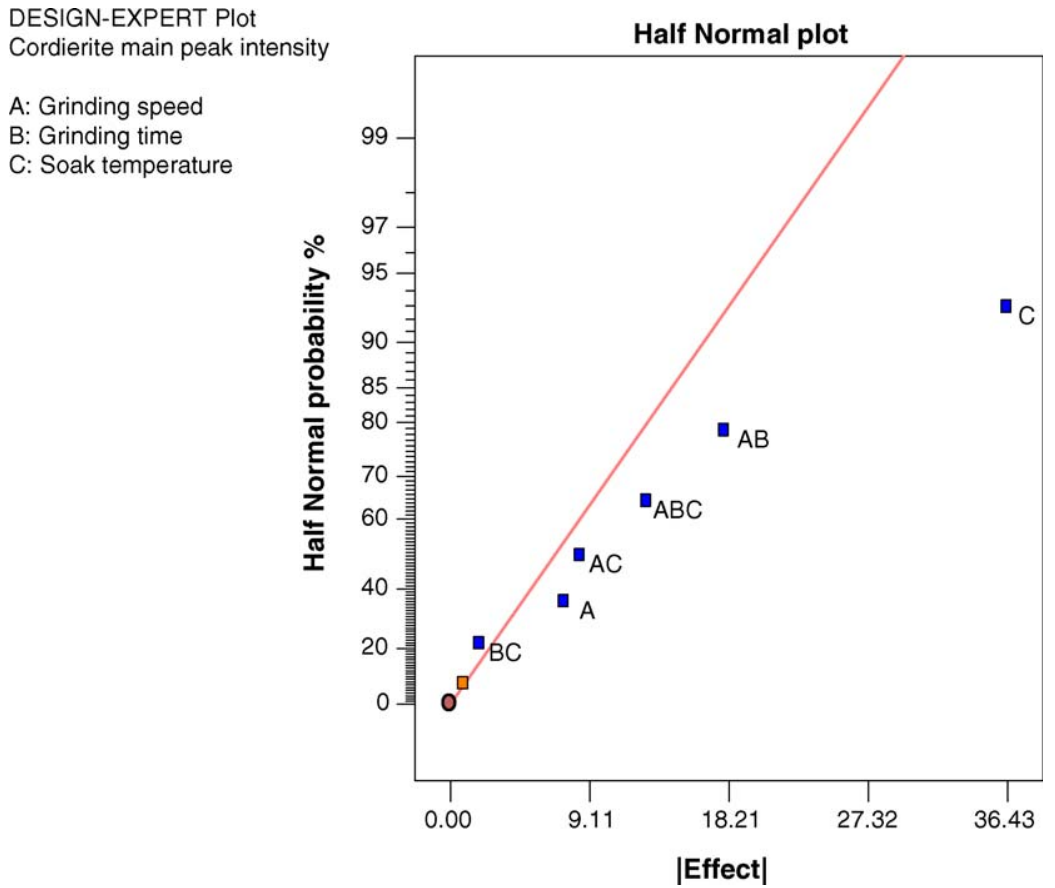

Fig. 4. Normal probability plot of the effects for the $2^{3}$ factorial. 
Table 6

Analysis of variance (ANOVA) table for the cordierite synthesis experiment in A and C

\begin{tabular}{|c|c|c|c|c|c|}
\hline Source & Sum of squares & Degrees of freedom & Mean square & $F$-value & Prob $>F$ \\
\hline Model & 3894.64 & 6 & 649.11 & 402.92 & 0.0381 \\
\hline A & 111.53 & 1 & 111.53 & 69.23 & 0.0761 \\
\hline $\mathrm{C}$ & 2653.93 & 1 & 2653.93 & 1647.36 & 0.0157 \\
\hline $\mathrm{AB}$ & 644.94 & 1 & 644.94 & 400.33 & 0.0318 \\
\hline $\mathrm{AC}$ & 145.44 & 1 & 145.44 & 90.28 & 0.0668 \\
\hline $\mathrm{BC}$ & 7.66 & 1 & 7.66 & 4.76 & 0.2737 \\
\hline $\mathrm{ABC}$ & 331.15 & 1 & 331.15 & 205.55 & 0.0443 \\
\hline Residual & 1.61 & 1 & 1.61 & & \\
\hline Cor total & 3896.25 & 7 & & & \\
\hline
\end{tabular}

$\mathrm{AB}$ and $\mathrm{ABC}$ interactions were also significant but not as strong as temperature.

According to the model, B (grinding duration) factor was not significant within the interval studied (15 and $60 \mathrm{~min}$ ). As was indicated in Fig. 1, there was no difference in the XRD patterns of 500-15-0-0-0 and 500-60-0-0-0 mixtures. A wider interval like 5-60 min may have helped observe a significant factor effect. $\mathrm{AB}$ interaction, however, was moderately significant. This meant, that the effect of grinding speed was different for different grinding durations.

After these experiments, we determined that the heat treatment temperature was the important parameter for cordierite synthesis. To investigate the heat treatment temperature in more detail, the specimens were heated at $1150{ }^{\circ} \mathrm{C}$ for $4 \mathrm{~h}$, and the results are shown in Fig. 5 .

Fig. 5 clearly shows the effect of grinding and the contribution of mechanochemical action on the synthesis of cordierite. Samples 300-15-1150-4-0 to 500-60-1150-4-0 were all able to produce cordierite at $1150{ }^{\circ} \mathrm{C}$. However, the as-mixed 0-0-1150-4-0 mixture was unable to produce cordierite after heating at the same temperature. Thus, a $150{ }^{\circ} \mathrm{C}$ reduction in the synthesis temperature for cordierite as compared to a previous study [8] was successfully accomplished via intensive grinding of the powder raw materials.

\subsubsection{Effect of grinding and additive on cordierite synthesis}

In this part of the study, the combination of grinding and additive effect on the cordierite synthesis temperature was studied. The as-mixed mixture with $5 \mathrm{wt} . \%$ magnesium borate was ground at $300 \mathrm{rpm}$ for $60 \mathrm{~min}$. The ground mixture was compacted and fired at 1000, 1050, 1100 and $1150{ }^{\circ} \mathrm{C}$ for $4 \mathrm{~h}$. The $\mathrm{X}$-ray diffraction patterns of heattreated specimens are shown in Fig. 6.

According to the XRD patterns, cordierite synthesis temperature was decreased down to nearly $1000{ }^{\circ} \mathrm{C}$. The use of longer soak times at that temperature may lead to further reductions in synthesis temperature but they were not tested in this project. These results showed that cordierite synthesis temperature was decreased nearly by $250{ }^{\circ} \mathrm{C}$ via the use of additives and mechanochemical synthesis.

\subsection{Differential thermal analyses (DTA)}

The results of DTA measurement for ground and asmixed mixtures are shown in Fig. 7. The intermediate step of

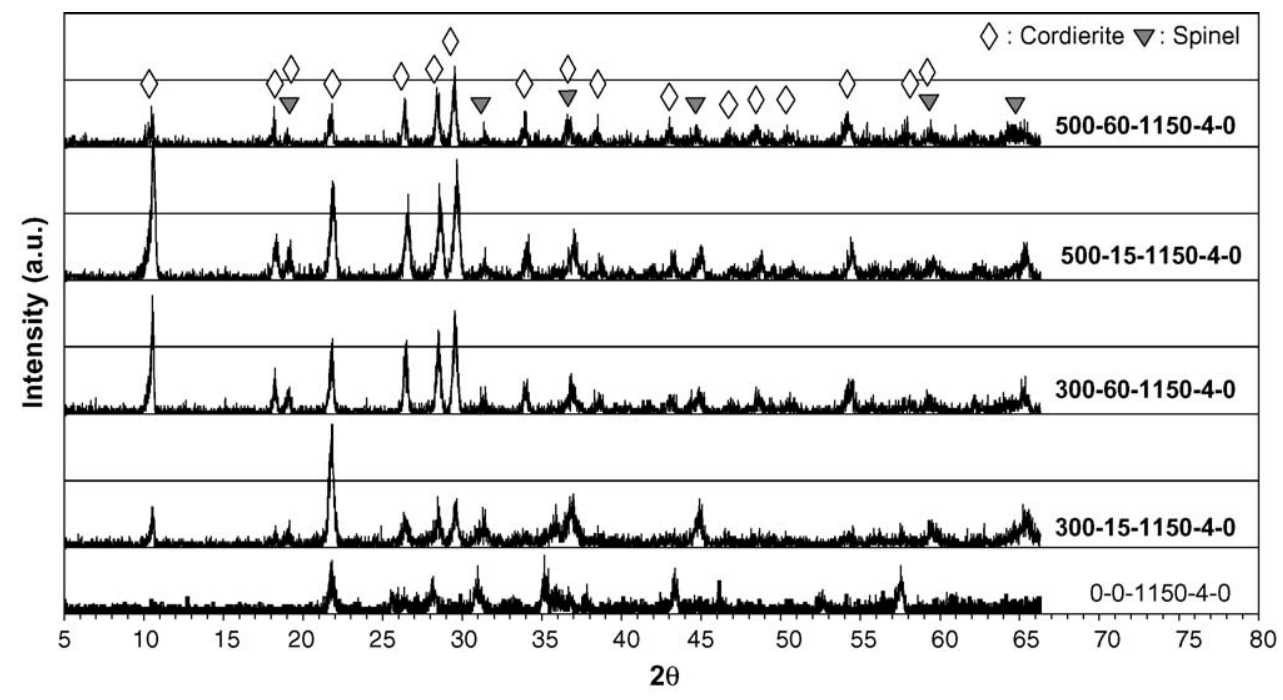

Fig. 5. XRD patterns of the as-mixed and ground samples that were heated at $1150{ }^{\circ} \mathrm{C}$. 


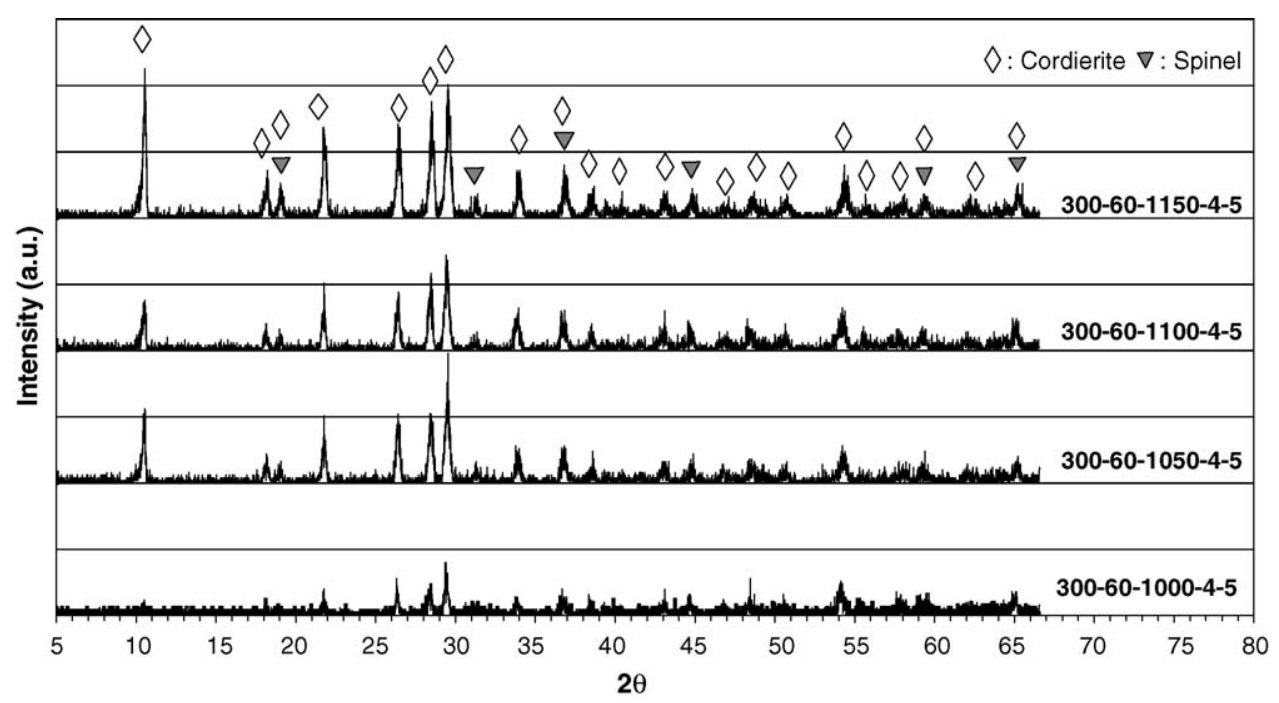

Fig. 6. XRD patterns of the ground samples with $5 \mathrm{wt} . \%$ magnesium borate additive that were heated at different temperatures.

the gibbsite dehydration peak at nearly $250{ }^{\circ} \mathrm{C}$ was observed in the as-mixed mixture. The endothermic peak at $290{ }^{\circ} \mathrm{C}$ showed dehydration of aluminium hydroxide. The peak was shifted to lower temperature when grinding time and speed were increased. The endothermic peak intensity also decreased on further grinding. These were attributed to the destruction of crystal structure as a result of extensive grinding, and local increases in temperature during grinding.

The small endothermic peak observed in as-mixed mixture at $520{ }^{\circ} \mathrm{C}$ corresponded to kaolinite dehydroxylation. This peak was very weak and again shifted to lower temperatures with increasing grinding times.

The as-mixed sample also had a small endothermic depression at $960{ }^{\circ} \mathrm{C}$, corresponding to the talc dehydroxylation and its transformation to enstatite [10]. The samples mechanochemically treated showed a disordered phase whose decomposition was easier and took place at comparatively lower temperatures.

A small exothermic peak at $1000{ }^{\circ} \mathrm{C}$ was observed in the as-mixed sample. This peak was due to the transformation of the non-crystalline structure of the kaolinite into a spinel or premullite phase. This peak appeared at $940{ }^{\circ} \mathrm{C}$ in the 500 15-0-0-0 mixture. This peak was also observed in the further ground mixtures 300-60-0-0-0 and 500-60-0-0-0. The intensity of this peak slightly increased in the 300-60-0-00 . However, there were no important temperature variations in the peak positions.

\subsection{Microstructural analyses (SEM)}

Grinding and additive effects on microstructure of cordierite were inspected by using SEM. Backscattered

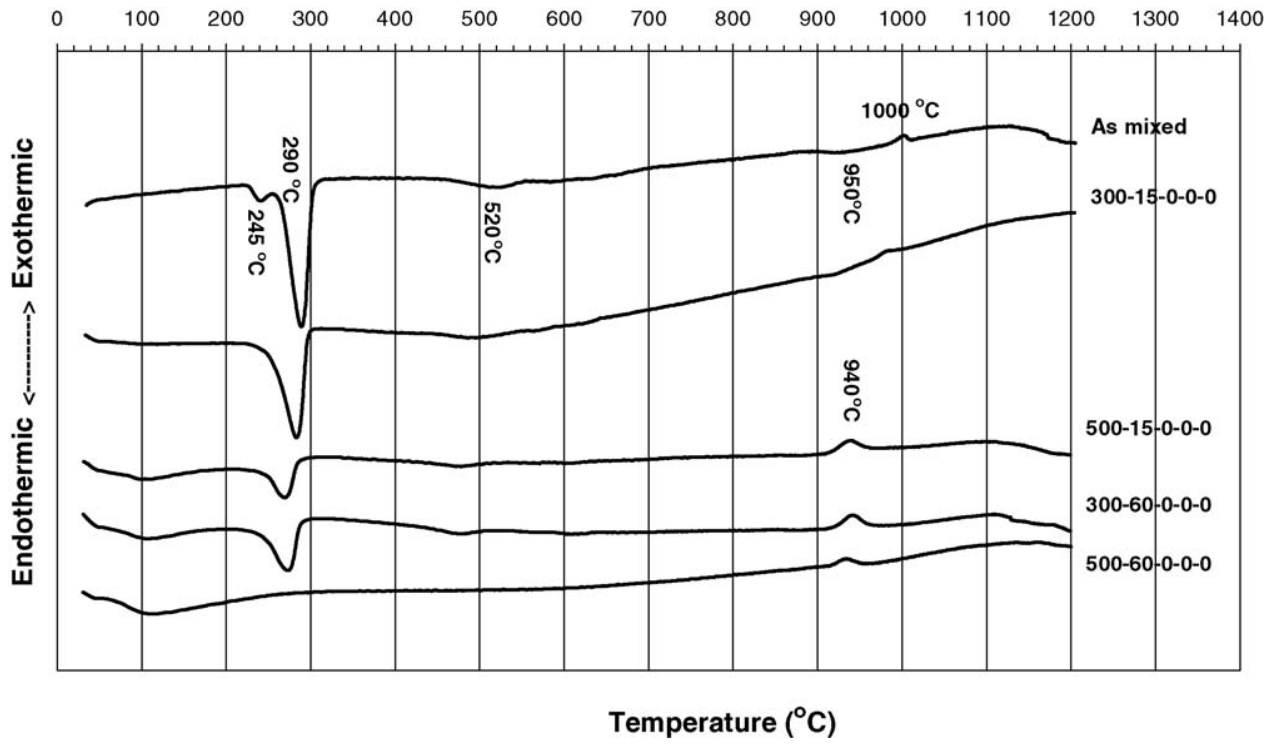

Fig. 7. DTA analysis of ground and unground mixtures. 


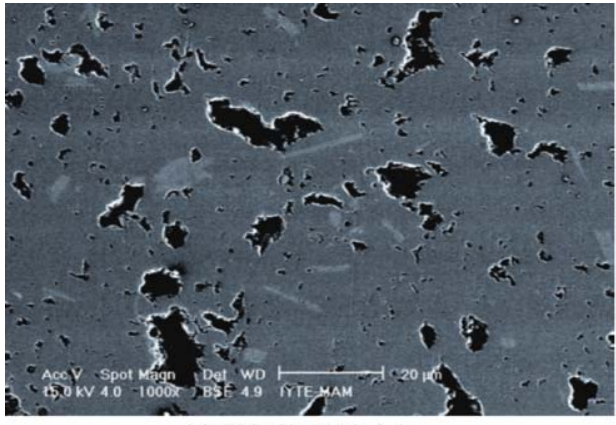

(a) $300-60-1150-4-0$

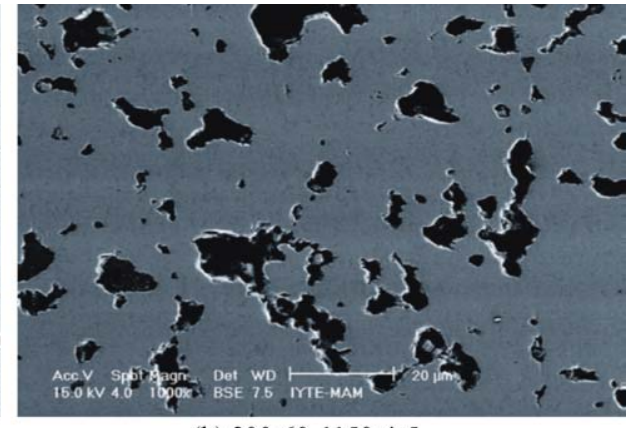

(b) $300-60-1150-4-5$

Fig. 8. Comparison of additive effect on the cordierite microstructure.

electron images (BSE) of polished sections of selected samples which were produced by grinding at $300 \mathrm{rpm}$ for $60 \mathrm{~min}$ and followed by heating at $1150{ }^{\circ} \mathrm{C}$ for $4 \mathrm{~h}$ are shown in Fig. 8a and b. One of the samples contained 5 wt.\% of magnesium borate (Fig. 8b). Angular and needle-like light grey areas were observed in the sample without additive. Such areas were analyzed by EDS and were found to contain a higher proportion of aluminium. However, such an aluminium-rich phase was not detected in the sample with additives.

Both samples displayed bi-modal pore size distributions including 1-2 $\mu \mathrm{m}$ and 5-20 $\mu \mathrm{m}$ pores. The proportion of fine pores $(1-2 \mu \mathrm{m})$ was significantly reduced in the sample with 5 wt. $\% 2 \mathrm{MgO} \cdot \mathrm{B}_{2} \mathrm{O}_{3}$ additive (Fig. $8 \mathrm{~b}$ ) compared to the sample without additive (Fig. 8a). Pores were angular in the first sample and they were rounded in the latter.

\section{Conclusions}

Cordierite is generally synthesized at $1300{ }^{\circ} \mathrm{C}$ by conventional solid state reaction. On the contrary in this study, cordierite was synthesized at $1150{ }^{\circ} \mathrm{C}$ by mechanochemical technique.

The combined effect of grinding and additive on cordierite synthesis was investigated. In this case, cordierite synthesis temperature was decreased down to nearly $1000{ }^{\circ} \mathrm{C}$. These results showed that cordierite synthesis temperature was successfully decreased by $300{ }^{\circ} \mathrm{C}$ via the simultaneous use of additive and intensive grinding.

\section{Acknowledgement}

The authors would like to thank the Izmir Institute of Technology for providing financial support through research grant 2002-IYTE-08.

\section{References}

[1] S.H. Knickerbocker, A.H. Kumar, L.W. Herron, Cordierite glassceramics for multilayer ceramic packing, Am. Ceram. Soc. Bull. 72 (1) (1993) 90-95.
[2] F.A. Costa Oliveira, C.J. Fernandes, Mechanical and thermal behaviour of cordierite-zirconia composites, Ceram. Int. 28 (2002) 79-91.

[3] W.C. Mohr, Development of properties in cordierite kiln furniture, Am. Ceram. Soc. Bull. 56 (4) (1977) 428-430.

[4] Y. Kobayashi, K. Sumi, E. Kato, Preparation of dense cordierite ceramics from magnesium compounds and kaolinite without additives, Ceram. Int. 26 (2000) 739-743.

[5] M. Awano, H. Takagi, Y. Kuwahara, Grinding effects on the synthesis and sintering of cordierite, J. Am. Ceram. Soc. 75 (9) (1992) 2535-2540.

[6] C.A. Bertran, N.T. da Silva, G.P. Thim, Citric acid effect on aqueous sol-gel cordierite synthesis, J. Non-Cryst. Solids 273 (2000) 140-144.

[7] Ö. Çakır, Production of Cordierite from Domestic Raw Materials, M.Sc. thesis, 1981. Middle East Technical University, Ankara.

[8] R.S. Lamar, M.F. Warner, Reaction and fired property studies of cordierite compositions, J. Am. Ceram. Soc. 37 (12) (1954) 602-610.

[9] S. Kurama, N. Ay, Effect of Grinding Time and $\mathrm{MgO}$ Source on Cordierite Formation, Am. Ceram. Soc. Bull. 81 (11) (2002) 58-61.

[10] S. Tamborenea, A.D. Mazzoni, E.F. Aglietti, Mechanochemical activation of minerals on the cordierite synthesis, Thermochim. Acta 411 (2004) 219-224.

[11] E. Kostic, S. Kiss, S. Boskovic, S. Zec, Mechanical activation of the gamma to alpha transition in $\mathrm{Al}_{2} \mathrm{O}_{3}$, Powder Technol. 91 (1997) 49-54.

[12] Y.M. Chiang, D.P. Brinie III, W.D. Kingery, Physical Ceramics, John Wiley \& Sons Inc., New York, 1997.

[13] J.-M. Wu, S.-P. Hwang, Effects of $\left(\mathrm{B}_{2} \mathrm{O}_{3}, \mathrm{P}_{2} \mathrm{O}_{5}\right)$ additives on microstructural development and phase-transformation kinetics of stoichiometric cordierite glasses, J. Am. Ceram. Soc. 83 (5) (2000) 1259-1265.

[14] K. Sumi, Y. Kobayashi, E. Kato, Low-Temperature fabrication of cordierite ceramics from kaolinite and magnesium hydroxide mixtures with Boron Oxide Additions, J. Am. Ceram. Soc. 82 (3) (1999) 783-785.

[15] S. Kurama, E. Ozel, N. Ay, Synthesis and sintering of cordierite at low temperature from kaolin and magnesium hydroxide, Key Eng. Mater. 264-268 (2004) 925-928.

[16] M.S. Kırıkoğlu, A. Sümer, S.G. Özkan, G. Özden, Investigation of some physical and chemical properties with respect to processing of kaolin samples from Sivas deposits in Turkey, Key Eng. Mater. 264 268 (2004) 1423-1426.

[17] Omya Mining Company, Product Information for Egyptian Talc Et 5, Istanbul, 2004.

[18] E. Yalamaç, Preparation of Fine Spinel and Cordierite Ceramic Powders by Mechano-chemical Techniques, M.Sc. Thesis, 2004. Izmir Institute of Technology, Izmir.

[19] E. Yalamaç, S. Akkurt, M. Çiftçioğlu, Low temperature synthesis of spinel powders by mechanical grinding, Key Eng. Mater. 264-268 (2004) 53-56.

[20] S. Chegrouche, A. Bensmaili, Removal of Ga(III) from aqueous solution by adsorption on activated bentonite using a factorial design, Water Res. 36 (2002) 2894-2904.

[21] H. Harris, W. Lautenberger, Strategy of Experimentation, E.I. Dupont de Nemours \& Co. Inc. Short Course Notes, 1976. 